\title{
Bacterial influence on the maintenance of symbiotic yeast through Drosophila metamorphosis
}

Running title: Bacterial influence on yeast maintenance

Robin Guilhot $^{1 *}$, Antoine Rombaut ${ }^{1}$, Anne Xuéreb $^{1}$, Kate Howell ${ }^{2}$, Simon Fellous $^{1}$

${ }^{1}$ CBGP, INRAE, CIRAD, IRD, Montpellier SupAgro, Univ Montpellier, Montpellier, France

${ }^{2}$ Faculty of Veterinary and Agricultural Sciences, University of Melbourne, Parkville, Vic 3010, Australia

*corresponding author's email address: guilhoro@gmail.com

Key words: maintenance through metamorphosis, symbiosis, microbial interactions, Drosophila, Saccharomyces cerevisiae, extracellular bacteria 
bioRxiv preprint doi: https://doi.org/10.1101/2020.05.31.126185; this version posted June 1, 2020. The copyright holder for this preprint (which was not certified by peer review) is the author/funder. All rights reserved. No reuse allowed without permission.

\section{Summary statement}

Bacterial symbionts of Drosophila influence yeast maintenance through fly metamorphosis, a novel observation that may have consequences for the evolution of insect-yeast-bacteria interactions. 


\section{Abstract}

2 Interactions between microbial symbionts of metazoan hosts are emerging as key features of 3 symbiotic systems. Little is known about the role of such interactions on the maintenance of 4 symbiosis through host's life cycle. We studied the influence of symbiotic bacteria on the 5 maintenance of symbiotic yeast through metamorphosis of the fly Drosophila melanogaster. 6 To this end we mimicked the development of larvae in natural fruit. In absence of bacteria 7 yeast was never found in young adults. However, yeast could maintain through 8 metamorphosis when larvae were inoculated with symbiotic bacteria isolated from $D$. 9 melanogaster faeces. Furthermore, an Enterobacteriaceae favoured yeast transstadial 10 maintenance. Because yeast is a critical symbiont of D. melanogaster flies, bacterial influence 11 on host-yeast association may have consequences for the evolution of insect-yeast-bacteria tripartite symbiosis and their cooperation. 


\section{Introduction}

Metazoans often form associations with non-obligatory symbiotic microorganisms. Microbial symbiont can influence host phenotype, and hosts determine symbiont multiplication and dispersal (Ferrari and Vavre, 2011). The importance of interactions between microorganisms is relatively better understood in the context of parasitism than in the context of beneficial symbionts (Alizon et al., 2013; Tollenaere et al., 2016; Zélé et al., 2018). Beneficial microbial symbionts can nonetheless interact in a wide variety of manners (Comolli, 2014; Seth and Taga, 2014; Hassani et al., 2018) and affect both the dynamics of each microorganism and the phenotype of their host (Wargo and Hogan, 2006; Newell and Douglas, 2014; Callens et al., 2018; Gould et al., 2018; Sommer and Newell, 2019).

Fungi-bacteria interactions are well described microbial interactions due to their importance in human health, industry and domestic life (Kobayashi and Crouch, 2009; Jouhten et al., 2016; Carbonetto et al., 2018). In the wild, yeasts and other fungi associate with extracellular bacteria in a wide variety of habitats, including decaying plant materials where they interact with the larvae and adults of saprophagous insects such as Drosophila flies. Symbioses between Drosophila and either yeast and bacteria have however been largely studied separately. Each type of microorganism affects Drosophila physiology, nutrition, reproduction and behavior (Ryu et al., 2008; Anagnostou et al., 2010; Shin et al., 2011; Storelli et al., 2011; Becher et al., 2012; Broderick and Lemaitre, 2012; Wong et al., 2014) and may maintain through - a variable part of - Drosophila life cycle (Bakula, 1969; Starmer et al., 1988; Hoang et al., 2015; Pais et al., 2018). In natural fruit, D. melanogaster larval development can be impossible, or largely compromised, in absence of yeast (Becher et al., 2012), suggesting symbiosis with yeast may not be dispensable for larvae. A handful of studies considering both fungi and bacteria showed that direct interaction between yeast and bacteria can modulate fly behavior (Fischer et al., 2017) and that bacteria can affect fly attraction to yeast (Leitão-Gonçalves et al., 2017). There is to date little data on how interactions between microbial symbionts affect their transmission from the host or maintenance among host life stages, which would have wide consequences for the ecological dynamics of the microorganisms, and consequently, the evolution of their symbiosis with flies.

It is established that Drosophila flies contribute to bacteria and yeast dynamics through effects on local multiplication and dispersal (Gilbert, 1980; Ganter, 1988; Starmer et al., 
1988; Chandler et al., 2012; Stamps et al., 2012; Buser et al., 2014). Saccharomyces yeast, for example, attracts adult flies with volatiles, these adults then acquire the microorganism and later inoculate it in fruit where larvae develop. An alternative mean of insect vectoring for symbiotic bacteria and yeast of larvae would rely on the transstadial maintenance, from the larval to the adult stage. It would enable the colonization of freshly emerged adults by larval symbionts and, provided they maintain and are shed later in life, their possible dispersal to new patches of resources. The maintenance of yeast or bacteria throughout the Drosophila life cycle have been investigated (Rohlfs and Hoffmeister, 2005; Pais et al., 2018), including maintenance from larvae to adults through metamorphosis (i.e. transstadial maintenance or transstadial transmission) (Bakula, 1969; Starmer et al., 1988; Ridley et al., 2012; Duneau and Lazzaro, 2018). To our knowledge, how interactions between microbial symbionts affect symbiont maintenance through Drosophila life stages remains however unknown. Here, we investigated the maintenance of a wild isolate of Saccharomyces cerevisiae yeast from larvae to young adults Drosophila melanogaster. We found that yeast presence in adults only occurred when larvae were associated with symbiotic bacteria and its frequency depended on the identity of these bacteria. 


\section{Material and methods}

62

\section{Biological material}

We used a Drosophila melanogaster (Meigen, 1830) Oregon-R strain usually maintained on

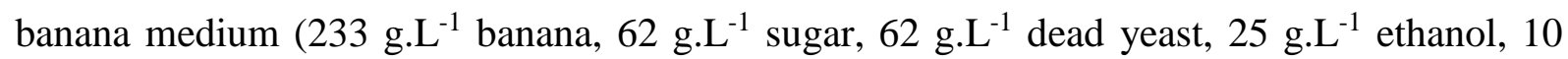
g.L $\mathrm{L}^{-1}$ agar and 5 g. $\mathrm{L}^{-1}$ nipagin) at $21^{\circ} \mathrm{C}$ with a $14 \mathrm{~h} / 10 \mathrm{~h}$ day-night cycle. The four bacterial strains used had been isolated from feces of adult Oregon- $\mathrm{R}$ flies and had been described in Guilhot et al. (2019). Bacterial strains were identified as Staphylococcus sp. (accession number MK461976 in the NCBI database), Enterococcus sp. (MK461977), an Enterobacteriaceae (MK461978) and an Actinobacteria (MK461979). The taxonomic resolution of our analyses is unfortunately modest and these bacteria do not usually dominate the Drosophila microbiota. However similar strains had already been identified as associated with Drosophilids (Chandler et al., 2011; Staubach et al., 2013). More importantly, microbial species and strains can evolve rapidly and with large consequences on their effects on host phenotype (Winans et al., 2017; Martino et al., 2018). For this reason, the proper description of symbiont effects on host phenotype in relevant experimental conditions (Guilhot et al. 2019) may be more important than high taxonomical resolution to understand symbiosis.

The yeast Saccharomyces cerevisiae (Meyen ex Hansen, 1883) strain was isolated from a wild Drosophilid in the 'Le Domaine de l'Hortus' vineyard, near Montpellier in Southern France.

\section{Experimental design}

The main experiment was conducted on sterile vials. Each experimental unit consisted of twenty D. melanogaster eggs free of cultivable bacteria and yeast deposited on an artificial wound of a surface-sterilized grape berry that was inoculated, or not, with specific microorganisms. Eggs were laid by conventionally-reared D. melanogaster Oregon-R females on solidified grape juice, which contained the antibiotic streptomycin (1 mg.L $\mathrm{L}^{-1}$, from a standard streptomycin solution of $1 \mathrm{mg} \cdot \mathrm{ml}^{-1}$ in $1 \mathrm{mM}$ EDTA (Sigma-Aldrich ref. 85886)) in order to remove parental bacteria. Grape berries were surface-sterilized; they were hence dipped in a $2 \%$ bleach solution, rinsed with sterile water and dried before use. We ensure these procedures were efficient: no cultivable bacteria or yeast were found in surfacesterilized berries and eggs homogenates. Every grape berry received $10^{4} \mathrm{~S}$. cerevisiae yeast cells suspended in $10 \mu \mathrm{l}$. Berries inoculated with $S$. cerevisiae were then allocated to six 
different bacterial treatments: no bacteria (control, $\mathrm{n}=18$ ); one of the four bacterial strains described above $\left(10^{4}\right.$ cells of the same type: $\mathrm{n}($ Staphylococcus $)=13, \mathrm{n}($ Enterococcus $)=13$, $\mathrm{n}($ Enterobacteriaceae $)=11, \mathrm{n}($ Actinobacteria $)=13)$; and a mixture of the four bacteria $\left(2.5 \times 10^{3}\right.$ cells of each type, $\left.n=9\right)$. Replicates were organized in eleven blocks launched over four days.

Newly formed pupae were aseptically removed daily from their larval container and placed in a sterile new vial until adult emergence. This procedure mimicked natural insect behavior as D. melanogaster larvae usually crawl out of their substrate before pupation (Sokolowski et al., 1986; Woltz and Lee, 2017), which incidentally prevent the exposure of young adults to the microorganisms present in the larval substrate. It was not logistically feasible to process every adult independently. We therefore elected to assess microbial content in groups of adults that emerged on the same day. For each grape berry, we randomly selected a single pupa and pooled all the adults, females as males, that emerged on the day as this pupa. This protocol allowed the detection of yeast (and bacterial) cells associated with freshly emerged adults that may have been present externally or internally. Sampled adults were homogenized in sterile PBS using a Tissue Lyser II (Qiagen) and $\emptyset 3 \mathrm{~mm}$ glass balls. Serially diluted fly samples were plated on Lysogeny Broth (LB) plates to count microbial cells after incubation at $24^{\circ} \mathrm{C}$. Colonies of the five microbial symbionts (yeast and bacteria) were distinguished according to their morphology (see Guilhot et al. 2019).

Effects of bacteria on yeast development in the larval fruit may explain some of our results. We hence collected the remaining juice from grape berries two days after the formation of the last pupa. Although quantifying yeast in fruit when larvae were feeding would have been informative too, we elected to not disturb the development of the larvae and waited the larvae left their substrate. Serially diluted fruit samples were plated on LB plates to count yeast colonies at $24^{\circ} \mathrm{C}$. As above, microbial colonies were distinguished based on their morphology.

In parallel to the main experiment, bacteria were also inoculated without yeast on cubes of laboratory medium (which contains dead yeast) following the procedure above to assess bacteria transstadial maintenance in their environment of origin (i.e. the banana medium used to rear the fly colony and described above). The six different bacterial treatments were: no bacteria (control, $\mathrm{n}=12$ ); one of the four bacterial strains described above ( $\mathrm{n}$ $($ Staphylococcus $)=12, \mathrm{n}($ Enterococcus $)=7, \mathrm{n}($ Enterobacteriaceae $)=11, \mathrm{n}($ Actinobacteria $)$ 
$124=11)$; and a mixture of the four bacteria $(\mathrm{n}=14)$. Replicates were organized in fifteen blocks

125 launched over four days.

\section{Statistical analyses}

127 We hypothesized larval bacteria would affect yeast transstadial maintenance. We estimated this phenomenon in groups of 1 to 11 freshly emerged adults (median $=5$, IQR $=4$ ). Yeastpositive samples contained 1 to 150 cells per adult fly (Fig. S1). This variation was not investigated statistically due to low statistical power. Whether live yeast cells were present or not was analyzed using a generalized linear model with binomial distribution and logit link function. Tested factors comprised bacterial treatment, number of adults in the groups, yeast concentration in the fruit, age of the adults and experimental block. Statistical power did not enable testing the interaction between bacterial treatment and number of adults in the groups (but see Fig. S2). Because we used groups of adult flies it was mandatory to take into account the number of individuals per pool. The biological material employed (i.e. wild and laboratory strains and populations) informs on the factors that can influence transstadial symbiont maintenance in a qualitative fashion, but could not indicate their quantitative occurrence in the field. Backward model selection allowed to eliminate non-significant terms (i.e. yeast concentration in the fruit and age of the pooled flies) from the initial complete model. Contrasts were used to detect significant differences between bacterial treatment levels. Numbers of replicates varied among bacterial treatments due to differential larval mortality. However, the analysis of larval survival revealed no significant effect of the bacteria on this trait (Guilhot et al., 2019).

145 To study the effect of the bacterial treatment on the yeast concentration (log-transformed) in 146 larval fruit substrate, we used a linear mixed model with Restricted Maximum Estimate Likelihood. Experimental block was defined as a random factor. 


\section{Results}

150 Bacterial treatment significantly affected $S$. cerevisiae presence in freshly emerged adult flies

$151\left(\chi^{2}=20.30, \mathrm{df}=5, \mathrm{p}=0.001\right)$. Yeast was never observed in adult flies that emerged from

152 control treatments, unlike treatments with bacteria at the larval stage (contrast 'All treatments

153 with bacteria' vs 'Control': $\chi^{2}=11.2, \mathrm{df}=1, \mathrm{p}<0.0001$ ) (Fig. 1). Young adult flies that had

154 developed with the Enterobacteriaceae alone or in mixture with the other bacteria were more

155 likely to harbor live yeast cells than the other treatments with bacteria at the larval stage

156 (contrast 'With Enterobacteriaceae' vs 'All other treatments with bacteria': $\chi^{2}=4.52$, df $=1, p$

$157=0.03$ ) (Fig. 1). As expected, the number of individuals in the assayed pool significantly and

158 positively affected the likelihood of yeast observation $\left(\chi^{2}=7.54\right.$, df $\left.=1, p=0.01\right)$ (Fig. S2) -

159 supporting the need to include this factor in all the analyses. The age of freshly emerged adult

160 flies $\left(\chi^{2}=0.65, \mathrm{df}=1, \mathrm{p}=0.42\right)$ and the yeast concentration in the larval medium $\left(\chi^{2}=0, \mathrm{df}=\right.$ $1, \mathrm{p}=1$ ) had not significant influence on yeast presence in adults.

162

The bacterial treatment had no significant effect on the yeast concentration in the medium two days after the formation of the last pupa $\left(\mathrm{F}_{5,49}=1.18, \mathrm{p}=0.33\right)$ (Fig. 2). Yeast presence in fruit flesh was detected in all replicates but one.

Bacteria could be observed in young adults that emerged from most combinations of larval environment and bacterial treatment (Fig. S3). However, the proportion of bacteria-positive groups never exceeded 25\%. When bacteria were detected, load varied from 1 to 33 bacterial cells per adult fly (data not analyzed statistically). The observation of the inoculated bacteria in emerged adults shows these bacteria sampled in laboratory adults reared on artificial medium could establish symbiosis with larvae, even in fruit substrate. 


\section{Discussion}

172 Our most important result is that larval bacteria influenced yeast transstadial maintenance 173 (Fig. 1). In control treatments that were not inoculated by bacteria, yeast was never found in freshly emerged adult flies. On the contrary, the presence of bacteria at the larval stage favored yeast maintenance through host metamorphosis. In particular, inoculation by the Enterobacteriaceae bacterium (alone or in mixture) led to greater $S$. cerevisiae transstadial maintenance than the other bacterial treatments (Fig. 1). The propensity to favor yeast maintenance hence seemed to vary among bacteria.

It is well known that coinfecting symbionts (mutualistic as parasitic) often affect each other's horizontal transmission to new hosts in holometabolous insects (Azambuja et al., 2005; Fellous and Koella, 2009; Gendrin and Christophides, 2013; Hegde et al., 2015) and other multicellular organisms (Azambuja et al., 2005; Lass et al., 2013; Barret et al., 2016; Bonnet et al., 2017; Zélé et al., 2018). However, we know a single other case of microbial interactions affecting symbiont maintenance through complete metamorphosis: in Galleria mellonella butterflies, the bacterium Enterococcus mundtii interacts with host immunity during the pupal stage to shape adult bacterial microbiota (Johnston and Rolff, 2015). Although we used fresh fruit and a wild yeast strain, flies and bacteria were laboratory sourced. Our experiment hence shows bacteria affect yeast transstadial maintenance in D. melanogaster, but further work will be necessary to unveil the pervasiveness of this phenomenon in the field.

What mechanisms may underlie symbiont transstadial maintenance, and how did bacteria affect it? The maintenance of $S$. cerevisiae yeast and several bacterial strains through Drosophila metamorphosis are congruent with previous reports of the transstadial maintenance of extracellular microbial symbionts in Drosophilids (Bakula, 1969; Starmer et al., 1988; Ridley et al., 2012; Duneau and Lazzaro, 2018; Téfit et al., 2018), other Dipterans (Radvan, 1960; Capuzzo et al., 2005; Rochon et al., 2005; Damiani et al., 2008; Lauzon et al., 2009; Gendrin and Christophides, 2013; Nayduch and Burrus, 2017; Majumder et al., 2020) and other holometabolous insects (Hammer and Moran, 2019). Microbial symbionts could maintain on inner or outer walls of the pupal chamber (Kaltenpoth et al., 2010; Wang and Rozen, 2017). In Drosophila melanogaster, bacterial cells of Escherichia coli were found associated with the inner pupal membrane (Bakula, 1969). Alternatively, adults might retrieve symbionts by consuming their own meconium - the remaining of larval midgut that is excreted right after adult emergence (Moll et al., 2001; Broderick and Lemaitre, 2012; 
Gendrin and Christophides, 2013). The mechanism of bacterial influence on yeast maintenance through metamorphosis is not trivial either. The Enterobacteriaceae that favored yeast maintenance, despite presenting a wide metabolic spectrum (Guilhot et al., 2019), probably not improved fruit quality by concentrating or synthetizing nutrients (Ramiro et al., 2016) as had no significant effect on fly phenotype in this context (Guilhot et al., 2019). Besides, the concentration of yeast cells in fruit did not correlated with the presence of yeast in the freshly emerged adults and was not affected by the bacterial treatment (Fig. 2). This lack of quantitative relationships suggests yeast maintenance through metamorphosis may be determined by qualitative processes rather than mere cell numbers. Several bacteria are known to interact with Drosophila host signaling (e.g. Shin et al., 2011; Storelli et al., 2011). Symbiotic bacteria could therefore elicit host or yeast physiological responses in a way that would affect the likelihood of transstadial maintenance.

Yeast transstadial maintenance in D. melanogaster may have consequences for the spatial spread of the yeast and the evolution of the symbiosis. Yeast needs active transport by insect vectors to disperse among the ephemeral patch of resources formed by fruits (Starmer and Lachance, 2011). Drosophila adults contribute to such yeast dispersal through two nonexcluding mechanisms. First, it is well established that yeasts produce chemical volatiles that attract adult flies (Palanca et al., 2013; Buser et al., 2014; Scheidler et al., 2015; Anagnostou et al., 2016; Bellutti et al., 2018; Günther et al., 2019; Lewis and Hamby, 2019), which favors their acquisition and vectoring by insects to new resource patches (Buser et al., 2014). Whether this phenomenon reflects yeast adaptation to insect vectoring is however debated (Günther and Goddard, 2019). Second, yeast maintenance through Drosophila metamorphosis - as demonstrated here - would enable the dispersal to new resource patches of larval symbionts (e.g. fruit, possibly infested with insect larvae) by colonized emerging adults. Such continuity in symbiosis over the life-cycle selects larval symbionts for beneficial effects on host fitness (Ebert, 2013). The microbial strains the most beneficial to larval development (for example in terms of larval survival) would be the ones best dispersed to new resources patches by the vigorous or numerous adult hosts they favored the development of. Furthermore, the maintenance of larval microbial symbionts until adult emergence may also benefit the host as freshly emerged adults could be less susceptible to opportunistic pathogens due to symbiont prior presence (Blum et al., 2013; Johnston and Rolff, 2015; Obadia et al., 2017). To conclude, transstadial maintenance of larval symbionts has implication for the dynamics and evolution of both hosts and microorganisms, the effects of bacteria on yeast we 
236 report may therefore affect important aspects of symbiosis. These are new and anticipated 237 consequences of insect association with bacteria.

238 Symbiont-symbiont interactions are emerging as key features of numerous taxa (Ferrari and 239 Vavre, 2011; Álvarez-Pérez et al., 2019, Mathé-Hubert et al., 2019), including Drosophila 240 flies (Fischer et al., 2017; Gould et al., 2018). Studying microbial symbionts one by one may 241 be more tractable, however our experiment illustrates understanding the nature and diversity 242 of host-symbiont relationships necessitates encompassing the complexity of natural 243 communities. 


\section{Acknowledgements}

245 We thank Edouard Jurkevitch, Natacha Kremer and Elodie Vercken for critical reading of an

246 earlier version of this manuscript and Laure Benoit, Marie-Pierre Chapuis, Romain Gallet and

247 Philippe Gautier for methodological help.

\section{Competing interests}

250 No competing interests declared.

251

\section{Author contributions}

253 R.G., A.R. and S.F. designed the experiment. R.G., A.R., A.X. and S.F. ran the experiment. 254 K.H. collected the yeast isolate. R.G. and S.F. analyzed the data and wrote the manuscript.

\section{Funding}

257 This work was supported by French National Research Agency through the 'SWING' project 258 (ANR-16-CE02-0015) and by Agropolis Fondation under the reference ID 1505-002 through 259 the 'Investissements d'avenir' program (Labex Agro: ANR-10-LABX-0001-01).

\section{Data availability}

262 The dataset is available in the open data repository Zenodo (doi: 10.5281/zenodo.3546129)

263 (Guilhot et al., 2020). 


\section{References}

Alizon, S., De Roode, J.C. and Michalakis, Y. (2013). Multiple infections and the evolution of virulence. Ecology letters 16, 556-567.

Álvarez-Pérez, S., Lievens, B. and Fukami, T. (2019). Yeast-bacterium interactions: the next frontier in nectar research. Trends in plant science 24, 393-401.

Anagnostou, C., Dorsch, M. and Rohlfs, M. (2010). Influence of dietary yeasts on Drosophila melanogaster life-history traits. Entomologia Experimentalis et Applicata 136, 1-11.

Azambuja, P., Garcia, E.S. and Ratcliffe, N.A. (2005). Gut microbiota and parasite transmission by insect vectors. Trends in parasitology 21, 568-572.

Bakula, M. (1969). The persistence of a microbial flora during postembryogenesis of Drosophila melanogaster. Journal of invertebrate pathology 14, 365-374.

Barret, M., Guimbaud, J.F., Darrasse, A. and Jacques M.A. (2016). Plant microbiota affects seed transmission of phytopathogenic micro-organisms. Mol. Plant. Pathol. 17, 791-795.

Becher, P.G., Flick, G., Rozpędowska, E., Schmidt, A., Hagman, A., Lebreton, S., Larsson, M.C., Hansson, B.S., Piškur, J. and Bengtsson, M. (2012). Yeast, not fruit volatiles mediate Drosophila melanogaster attraction, oviposition and development. Functional Ecology 26, 822-828.

Bellutti, N., Gallmetzer, A., Innerebner, G., Schmidt, S., Zelger, R. and Koschier, E.H. (2018). Dietary yeast affects preference and performance in Drosophila suzukii. Journal of pest science 91, 651-660.

Blum, J.E., Fischer, C.N., Miles, J. and Handelsman, J. (2013). Frequent replenishment sustains the beneficial microbiome of Drosophila melanogaster. MBio 4, e00860-13.

Bonnet, S.I., Binetruy, F., Hernández-Jarguín, A.M. and Duron, O. (2017). The tick microbiome: why non-pathogenic microorganisms matter in tick biology and pathogen transmission. Frontiers in Cellular and Infection Microbiology 7, 236.

Broderick, N.A. and Lemaitre, B. (2012). Gut-associated microbes of Drosophila melanogaster. Gut microbes 3, 307-321. 
Buser, C.C., Newcomb, R.D., Gaskett, A.C. and Goddard, M.R. (2014). Niche construction initiates the evolution of mutualistic interactions. Ecology Letters 17, 1257-1264.

Callens, M., Watanabe, H., Kato, Y., Miura, J. and Decaestecker, E. (2018). Microbiota inoculum composition affects holobiont assembly and host growth in Daphnia. Microbiome 6, 56 .

Capuzzo, C., Firrao, G., Mazzon, L., Squartini, A. and Girolami, V. (2005). 'Candidatus Erwinia dacicola', a coevolved symbiotic bacterium of the olive fly Bactrocera oleae (Gmelin). International journal of systematic and evolutionary microbiology 55, 1641-1647.

Carbonetto, B., Ramsayer, J., Nidelet, T., Legrand, J. and Sicard, D. (2018). Bakery yeasts, a new model for studies in ecology and evolution. Yeast 35, 591-603.

Chandler, J. A., Lang, J. M., Bhatnagar, S., Eisen, J. A., and Kopp A. (2011). Bacterial communities of diverse Drosophila species: ecological context of a host-microbe model system. PLoS Genetics 7, e1002272.

Chandler, J.A., Eisen, J.A. and Kopp, A. (2012). Yeast communities of diverse Drosophila species: comparison of two symbiont groups in the same hosts. Appl. Environ. Microbiol. 78, 7327-7336.

Comolli, L.R. (2014). Intra-and inter-species interactions in microbial communities. Frontiers in microbiology 5, 629.

Damiani, C., Ricci, I., Crotti, E., Rossi, P., Rizzi, A., Scuppa, P., Esposito, F., Bandi, C., Daffonchio, D. and Favia, G. (2008). Paternal transmission of symbiotic bacteria in malaria vectors. Current Biology 18, R1087-R1088.

Duneau, D.F. and Lazzaro, B.P. (2018). Persistence of an extracellular systemic infection across metamorphosis in a holometabolous insect. Biology letters 14, 20170771.

Ebert, D. (2013). The epidemiology and evolution of symbionts with mixed-mode transmission. Annual Review of Ecology, Evolution, and Systematics 44, 623-643.

Fellous, S. and Koella, J.C. (2009). Infectious dose affects the outcome of the within-host competition between parasites. The American Naturalist 173, E177-E184. 
Ferrari, J. and Vavre, F. (2011). Bacterial symbionts in insects or the story of communities affecting communities. Philosophical Transactions of the Royal Society B: Biological Sciences 366, 1389-1400.

Fischer, C.N., Trautman, E.P., Crawford, J.M., Stabb, E.V., Handelsman, J. and Broderick, N.A. (2017). Metabolite exchange between microbiome members produces compounds that influence Drosophila behavior. Elife 6, e18855.

Ganter, P.F. (1988). The vectoring of cactophilic yeasts by Drosophila. Oecologia 75, 400404.

Gendrin, M. and Christophides, G.K. (2013). The Anopheles mosquito microbiota and their impact on pathogen transmission. In Anopheles mosquitoes-New insights into Malar. vectors. InTech.

Gilbert, D.G. (1980). Dispersal of yeasts and bacteria by Drosophila in a temperate forest. Oecologia 46, 135-137.

Gould, A.L., Zhang, V., Lamberti, L., Jones, E.W., Obadia, B., Korasidis, N., Gavryushkin, A., Carlson, J.M., Beerenwinkel, N. and Ludington, W.B. (2018). Microbiome interactions shape host fitness. Proceedings of the National Academy of Sciences 115, E11951-E11960.

Guilhot, R., Rombaut, A., Xuéreb, A., Howell, K. and Fellous, S. (2019). Environmental specificity in Drosophila-bacteria symbiosis affects host developmental plasticity. bioRxiv doi:10.1101/717702, version 3: peer-reviewed and recommended by PCI Evolutionary Biology doi:10.24072/pci.evolbiol.100085

Guilhot, R., Rombaut, A., Xuéreb, A., Howell, K. and Fellous, S. (2020). Data from: Bacterial influence on the maintenance of symbiotic yeast through Drosophila metamorphosis. Zenodo. https://zenodo.org/record/3546129\#.Xpj17XvgrIV

Günther, C.S. and Goddard, M.R. (2019) Do yeasts and Drosophila interact just by chance? Fungal Ecology 38, 37-43.

Günther, C.S., Knight, S.J., Jones, R. and Goddard, M.R. (2019). Are Drosophila preferences for yeasts stable or contextual? Ecology and evolution 9, 8075-8086. 
Hammer, T.J. and Moran, N.A. (2019). Links between metamorphosis and symbiosis in holometabolous insects. Philosophical Transactions of the Royal Society B 374, 20190068.

Hassani, M.A., Durán, P. and Hacquard, S. (2018). Microbial interactions within the plant holobiont. Microbiome 6, 58.

Hegde, S., Rasgon, J.L. and Hughes, G.L. (2015). The microbiome modulates arbovirus transmission in mosquitoes. Current opinion in virology 15, 97-102.

Hoang, D., Kopp, A., and Chandler, J. A. (2015). Interactions between Drosophila and its natural yeast symbionts - Is Saccharomyces cerevisiae a good model for studying the flyyeast relationship? PeerJ 3, e1116.

Johnston, P.R. and Rolff, J. (2015). Host and symbiont jointly control gut microbiota during complete metamorphosis. PLoS Pathogens 11, e1005246.

Jouhten, P., Ponomarova, O., Gonzalez, R. and Patil, K.R. (2016). Saccharomyces cerevisiae metabolism in ecological context. FEMS yeast research 16, fow080.

Kaltenpoth, M., Goettler, W., Koehler, S. and Strohm, E. (2010). Life cycle and population dynamics of a protective insect symbiont reveal severe bottlenecks during vertical transmission. Evolutionary ecology 24, 463-477.

Kobayashi, D.Y. and Crouch, J.A. (2009). Bacterial/fungal interactions: from pathogens to mutualistic endosymbionts. Annual review of phytopathology 47, 63-82.

Lass, S., Hudson, P.J., Thakar, J., Saric, J., Harvill, E., Albert, R. and Perkins, S.E. (2013). Generating super-shedders: co-infection increases bacterial load and egg production of a gastrointestinal helminth. Journal of the Royal Society Interface 10, 20120588.

Lauzon, C.R., McCombs, S.D., Potter, S.E. and Peabody, N.C. (2009). Establishment and vertical passage of Enterobacter (Pantoea) agglomerans and Klebsiella pneumoniae through all life stages of the Mediterranean fruit fly (Diptera: Tephritidae). Annals of the Entomological Society of America 102, 85 - 95.

Leitão-Gonçalves, R., Carvalho-Santos, Z., Francisco, A.P., Fioreze, G.T., Anjos, M., Baltazar, C., Elias, A.P., Itskov, P.M., Piper, M.D.W. and Ribeiro, C. (2017). Commensal 
bacteria and essential amino acids control food choice behavior and reproduction. PLoS Biology 15, e2000862.

Lewis, M.T. and Hamby, K.A. (2019). Differential impacts of yeasts on feeding behavior and development in larval Drosophila suzukii (Diptera: Drosophilidae). Scientific reports 9, 1-12.

Majumder, R., Sutcliffe, B., Taylor, P.W. and Chapman, T.A. (2020). Microbiome of the Queensland fruit fly through metamorphosis. Microorganisms 8, 795.

Martino, M.E., Joncour, P., Leenay, R., Gervais, H., Shah, M., Hughes, S., Gillet, B., Beisel, C. and Leulier, F. (2018). Cell host \& microbe 24, 109-119.

Mathé-Hubert, H., Kaech, H., Hertaeg, C., Jaenike, J. and Vorburger, C. (2019). Nonrandom associations of maternally transmitted symbionts in insects: The roles of drift versus biased cotransmission and selection. Molecular ecology 28, 5330-5346.

Moll, R.M., Romoser, W.S., Modrakowski, M.C., Moncayo, A.C. and Lerdthusnee, K. (2001). Meconial peritrophic membranes and the fate of midgut bacteria during mosquito (Diptera: Culicidae) metamorphosis. Journal of medical entomology 38, 29-32.

Nayduch, D. and Burrus, R.G. (2017). Flourishing in filth: house fly-microbe interactions across life history. Annals of the Entomological Society of America 110, 6-18.

Newell, P.D. and Douglas, A.E. (2014). Interspecies interactions determine the impact of the gut microbiota on nutrient allocation in Drosophila melanogaster. Appl. Environ. Microbiol. 80, 788-796.

Obadia, B., Güvener, Z.T., Zhang, V., Ceja-Navarro, J.A., Brodie, E.L., William, W.J. and Ludington, W.B. (2017). Probabilistic invasion underlies natural gut microbiome stability. Current Biology 27, 1999-2006.

Pais, I.S., Valente, R.S., Sporniak, M. and Teixeira, L. (2018). Drosophila melanogaster establishes a species-specific mutualistic interaction with stable gut-colonizing bacteria. PLoS Biology 16, e2005710.

Palanca, L., Gaskett, A.C., Günther, C.S., Newcomb, R.D. and Goddard, M.R. (2013). Quantifying variation in the ability of yeasts to attract Drosophila melanogaster. PLoS One $\mathbf{8}$, e75332. 
Ramiro, R.S., Pollitt, L.C., Mideo, N. and Reece, S.E. (2016). Facilitation through altered resource availability in a mixed-species rodent malaria infection. Ecology letters 19, 10411050 .

Radvan, R. (1960). Persistence of bacteria during development in flies. Folia Microbiologica $5,50$.

Ridley, E.V., Wong, A.C., Westmiller, S. and Douglas, A.E. (2012). Impact of the resident microbiota on the nutritional phenotype of Drosophila melanogaster. PloS One 7, e36765.

Rochon, K., Lysyk, T.J. and Selinger, L.B. (2005). Retention of Escherichia coli by house fly and stable fly (Diptera: Muscidae) during pupal metamorphosis and eclosion. Journal of medical entomology 42, $397-403$.

Rohlfs, M. and Hoffmeister, T.S. (2005). Maternal effects increase survival probability in Drosophila subobscura larvae. Entomologia Experimentalis et Applicata 117, 51-58.

Ryu, J.H., Kim, S.H., Lee, H.Y., Bai, J.Y., Nam, Y.D., Bae, J.W., Lee, D.G., Shin, S.C., Ha, E.M. and Lee, W.J. (2008). Innate immune homeostasis by the homeobox gene caudal and commensal-gut mutualism in Drosophila. Science 319, 777-782.

Scheidler, N.H., Liu, C., Hamby, K.A., Zalom, F.G. and Syed, Z. (2015). Volatile codes: correlation of olfactory signals and reception in Drosophila-yeast chemical communication. Scientific reports 5, 14059.

Seth, E.C. and Taga, M.E. (2014). Nutrient cross-feeding in the microbial world. Frontiers in microbiology 5, 350 .

Shin, S.C., Kim, S.H., You, H., Kim, B., Kim, A.C., Lee, K.A., Yoon, J.H., Ryu, J.H. and Lee, W.J. (2011). Drosophila microbiome modulates host developmental and metabolic homeostasis via insulin signaling. Science 334, 670-674.

Sokolowski, M.B., Bauer, S.J., Wai-Ping, V., Rodriguez, L., Wong, J.L. and Kent, C. (1986). Ecological genetics and behaviour of Drosophila melanogaster larvae in nature. Animal Behaviour 34, 403-408. 
Sommer, A.J. and Newell, P.D. (2019). Metabolic basis for mutualism between gut bacteria and its impact on the Drosophila melanogaster host. Appl. Environ. Microbiol. 85, e0188218.

Stamps, J.A., Yang, L.H., Morales, V.M. and Boundy-Mills, K.L. (2012). Drosophila regulate yeast density and increase yeast community similarity in a natural substrate. PLoS One 7, e42238.

Starmer, W.T., Peris, F. and Fontdevila, A. (1988). The transmission of yeasts by Drosophila buzzatii during courtship and mating. Animal behaviour 36, 1691-1695.

Starmer, W.T. and Lachance, M.A. (2011). Yeast ecology. In The Yeasts: a Taxonomic Study, pp. 65-83. Elsevier, Waltham, MA.

Staubach, F., Baines, J. F., Künzel, S., Bik, E. M. and Petrov, D. A. (2013). Host species and environmental effects on bacterial communities associated with Drosophila in the laboratory and in the natural environment. PloS One 8, e70749.

Storelli, G., Defaye, A., Erkosar, B., Hols, P., Royet, J. and Leulier, F. (2011). Lactobacillus plantarum promotes Drosophila systemic growth by modulating hormonal signals through TOR-dependent nutrient sensing. Cell metabolism 14, 403-414.

Téfit, M.A., Gillet, B., Joncour, P., Hughes, S. and Leulier, F. (2018). Stable association of a Drosophila-derived microbiota with its animal partner and the nutritional environment throughout a fly population's life cycle. Journal of insect physiology 106, 2-12.

Tollenaere, C., Susi, H. and Laine, A.L. (2016). Evolutionary and epidemiological implications of multiple infection in plants. Trends in plant science 21, 80-90.

Wang, Y. and Rozen, D.E. (2017). Gut microbiota colonization and transmission in the burying beetle Nicrophorus vespilloides throughout development. Appl. Environ. Microbiol. 83, e03250-16.

Wargo, M.J. and Hogan, D.A. (2006). Fungal - bacterial interactions: a mixed bag of mingling microbes. Current opinion in microbiology 9, 359-364. 
Winans, N.J., Walter, A., Chouaia, B., Chaston, J.M., Douglas, A.E. and Newell, P.D. (2017). A genomic investigation of ecological differentiation between free-living and Drosophilaassociated bacteria. Molecular ecology 26, 4536-4550.

Woltz, J.M. and Lee, J.C. (2017). Pupation behavior and larval and pupal biocontrol of Drosophila suzukii in the field. Biological control 110, 62-69.

Wong, A.C.N., Dobson, A.J. and Douglas, A.E. (2014). Gut microbiota dictates the metabolic response of Drosophila to diet. Journal of Experimental Biology 217, 1894-1901.

Zélé, F., Magalhães, S., Kéfi, S. and Duncan, A.B. (2018). Ecology and evolution of facilitation among symbionts. Nature communications $\mathbf{9 , 4 8 6 9 .}$ 


\section{Figures}

Fig. 1. Transstadial maintenance of Saccharomyces cerevisiae in response to bacterial treatment. Symbols indicate the proportion of groups of freshly emerged adult flies containing yeast per bacterial treatment $(n=$ number of adult groups per bacterial treatment). $95 \%$ binomial confidence intervals were calculated using normal approximation method. These results are qualitative as we used groups of adult flies to estimate yeast transstadial maintenance (Fig S2).

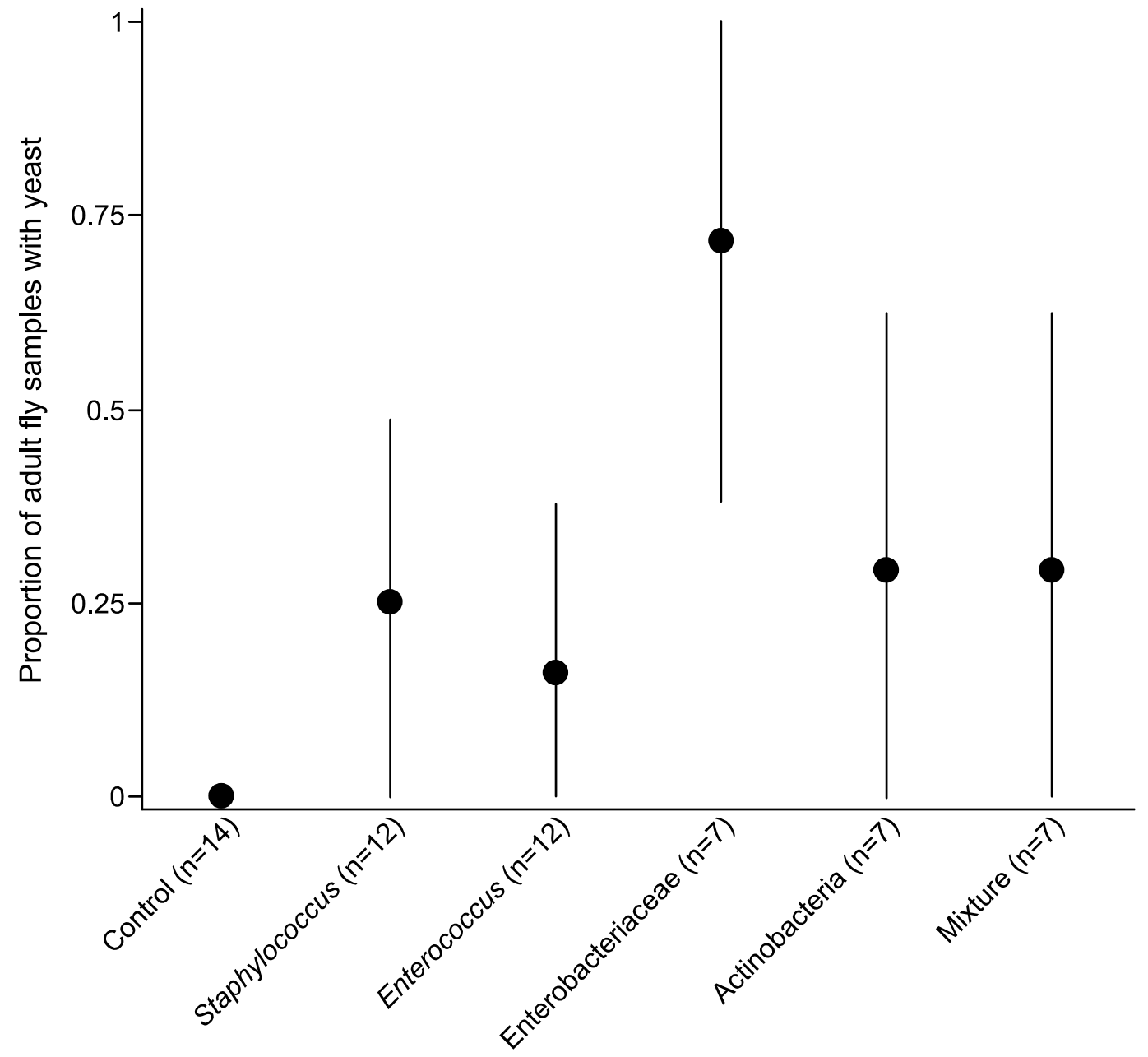

Bacterial treatment 
Fig. 2. Yeast concentration in grape berry flesh after the formation of the last pupa. Concentration is expressed in number of yeast cells per $200 \mu \mathrm{l}$ of fruit flesh. Symbols indicate mean \pm s.e.m.

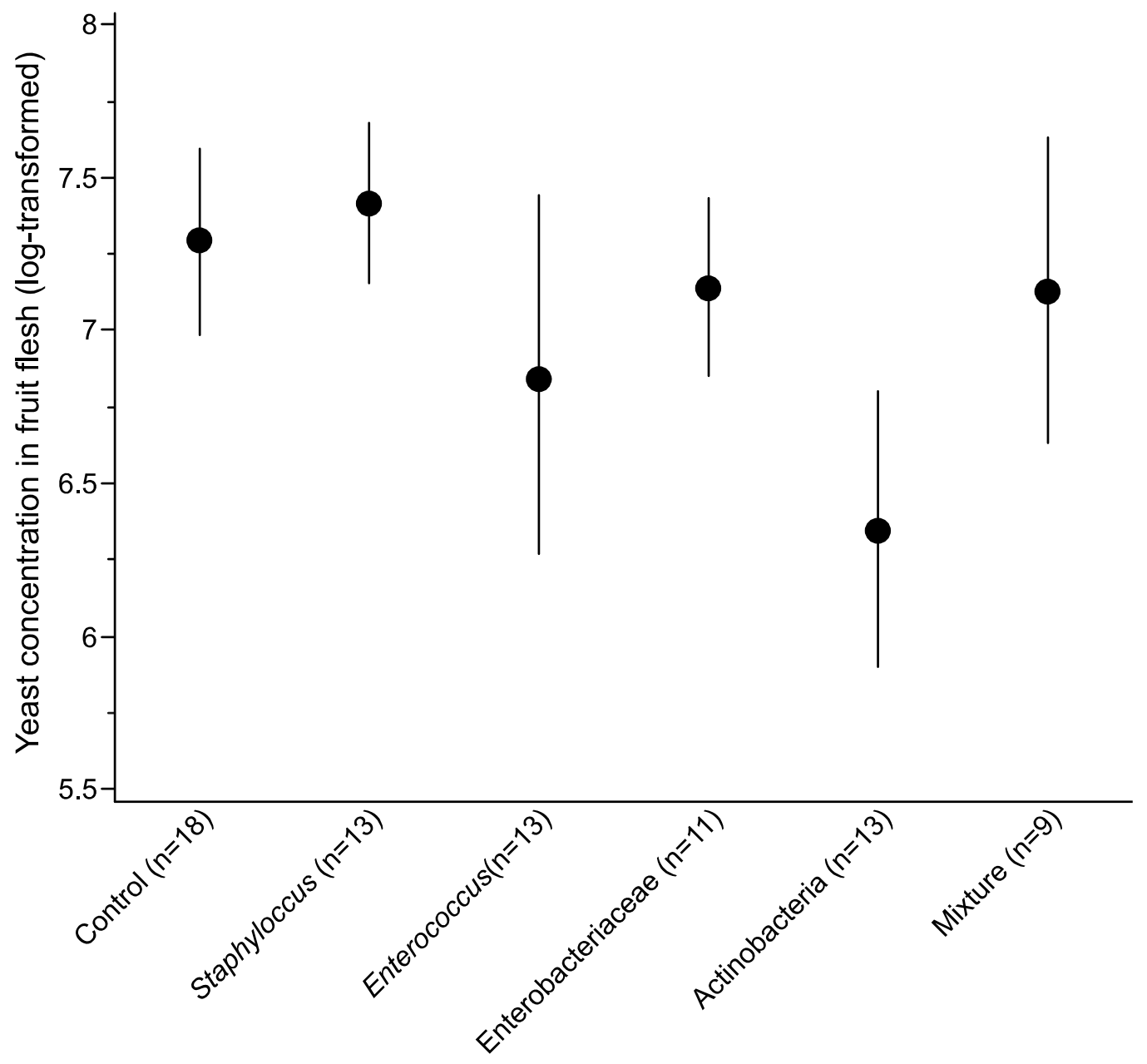

Bacterial treatment 